\title{
Roles of the complement system in alcohol-induced liver disease
}

\author{
Yi Zhou, Guandou Yuan, Fudi Zhong, and Songqing He \\ Division of Hepatobiliary Surgery, the First Affiliated Hospital of Guangxi Medical University, Nanning, China
}

Alcohol-induced liver disease (ALD) is a complex disorder, with a disease spectrum ranging from steatosis to steatohepatitis, cirrhosis, and hepatocellular carcinoma. Although the pathogenesis of ALD is incompletely understood and currently no effective drugs are available for ALD, several lines of evidence suggest that complement activation and oxidative stress play crucial roles in the pathogenesis of ALD. Complement activation can regulate the production of ROS and influence oxidative stress in ALD. Precise regulation of the complement system in ALD may be a rational and novel avenue to postpone and even reverse the progression of disease and simultaneously promote the repair of liver injury. In this mini-review, we briefly summarize the recent research progress, especially focusing on the role of complement and oxidative stress-induced transfer RNA-derived fragments, which might help us to better understand the pathogenesis of ALD and provide aid in the development of novel therapeutic strategies for ALD. (Clin Mol Hepatol 2020;26:677-685)

Keywords: Complement system proteins; Liver Diseases; Alcoholic; Molecular targeted therapy

\section{OVERVIEW OF THE COMPLEMENT SYSTEM}

Complement activation is a key part of the innate immune system, which plays a crucial role in the defense against microbial infections, healing of the host, and disposal of the products of inflammatory injury. ${ }^{1-3}$ The complement system consists of complement components, receptors, and regulatory factors. Most of the serum complement components are produced in the liver, and many complement receptors (CRs) are expressed in liver Kupffer cells and hepatic stellate cells. ${ }^{4-6}$ According to the recognition of different molecules, complement activation can be divided into three main pathways: the classical pathway $(C P)$, the alternative pathway (AP), and the lectin pathway (LP) (Fig. 1). ${ }^{7}$ The CP is triggered by $\mathrm{C} 1 \mathrm{q}$ recognition of antibodies bound to antigens or microbial surfaces, resulting in the activation of $\mathrm{C} 1 \mathrm{r}$ and C1s. The activated $\mathrm{C} 1 \mathrm{~s}$ then cleaves $\mathrm{C} 4$ and $\mathrm{C} 2$ to form $\mathrm{C} 3$ convertase (C4bC2b). The

\begin{abstract}
Abbreviations:
AFLD, alcoholic fatty liver disease; AH, alcoholic hepatitis; ALD, alcoholic liver disease; ALT, alamine aminotransferase; AP, alternative pathway; Asp, acylation stimulating protein; CP, classical pathway; CR1, complement receptor 1; Crry, complement receptor 1-related protein y; CRs, complement receptors; FB, factor $B ; F D$, factor $D ; F H$, factor $H$; Gly-tRFs, glycine tRNA-derived fragments; LP, lectin pathway; MAC, membrane attack complex; MBL, mannan binding lectin; PAMPs, pathogen-associated molecular patterns; ROS, reactive oxygen species; TLRs, toll-like receptors; TNF-a, tumor necrosis factor-a
\end{abstract}

\section{Corresponding author : Songqing $\mathrm{He}$}

Division of Hepatobiliary Surgery, the First Affiliated Hospital of Guangxi Medical University, No.6 Shuangyong Road, Nanning 530021, China

Tel :+86-15877170588, Fax: +86-0771-5350190

E-mail:dr_hesongqing@163.com

https://orcid.org/0000-0002-8966-2195

\section{Fudi Zhong}

Division of Hepatobiliary Surgery, the First Affiliated Hospital of Guangxi Medical University, No.6 Shuangyong Road, Nanning 530021, China

Tel: +86-13737704061, Fax: +86-0771-5624532

E-mail: andy020@126.com

https://orcid.org/0000-0003-2606-1285 
LP is similar to the CP; they share $C 3$ convertase (C4bC2b). However, the LP does not rely on antibodies to identify pathogenic components but uses mannan binding lectin (MBL) and ficolins to identify sugars or $\mathrm{N}$-acetylated groups on the surface of pathogens. In response, MBL-associated serine proteases (MASP1/ MASP3 and MASP2) are activated. ${ }^{8}$ The activated MASP1/MASP3 and MASP2 can cleave $C 2$ and $C 4$ to form $C 4 b C 2 b .{ }^{9,10}$ The AP is different from the $C P$ and $L P$; the $A P$ is initiated by $C 3$ itself. In the first step, the spontaneous hydrolysis of the thioester bond within $\mathrm{C} 3$ takes place, resulting in the formation of $\mathrm{C} 3\left(\mathrm{H}_{2} \mathrm{O}\right)$. Then, $\mathrm{C} 3\left(\mathrm{H}_{2} \mathrm{O}\right)$ recruits factor $\mathrm{B}(\mathrm{FB})$ to form a complex, which can be further cleaved by factor $D(F D)$, leading to the formation of $\mathrm{C} 3\left(\mathrm{H}_{2} \mathrm{O}\right) \mathrm{Bb}$. $\mathrm{C} 3\left(\mathrm{H}_{2} \mathrm{O}\right) \mathrm{Bb}$ is also a $\mathrm{C} 3$ convertase enzyme complex, which cleaves $\mathrm{C} 3$ to $\mathrm{C} 3 \mathrm{a}$ and $\mathrm{C} 3 \mathrm{~b}$. C3b can be added to $\mathrm{FB}$ and cleaved by $F D$, resulting in the formation of the $\mathrm{C} 3$ convertase $\mathrm{C} 3 \mathrm{bBb}$, which acts as an amplification loop of the complement system. ${ }^{11,12}$
The above three pathways produce C3 convertase and C5 convertase, which can cleave the central complement components $\mathrm{C} 3$ and $\mathrm{C} 5$, respectively, and generate effector molecules..$^{13}$ Anaphylatoxins, including $\mathrm{C} 3 \mathrm{a}$ and $\mathrm{C} 5 \mathrm{a}$, are important potent pro-inflammatory molecules that attract and activate immune cells. Opsonin C3b (or C4b) is deposited on the surface of pathogens or injured cells, and mediates immune adhesion and opsonization or induces cytolysis through the membrane attack complex (MAC). The MAC consists of $C 5 b, C 6, C 7, C 8$, and $C 9$, which can directly lyse targeted pathogens or damaged autologous cells. ${ }^{14,15}$

In recent years, the comprehensive evaluation of complement function has shown that the complement system not only plays a traditional role in the immune process but also participates in a variety of important physiological functions, such as lipid metabolism, the inflammatory response, coagulation, angiogenesis, and tissue repair. ${ }^{2,10,16-20} \mathrm{~A}$ growing number of studies have revealed that the complement system also plays essential roles in the prog-

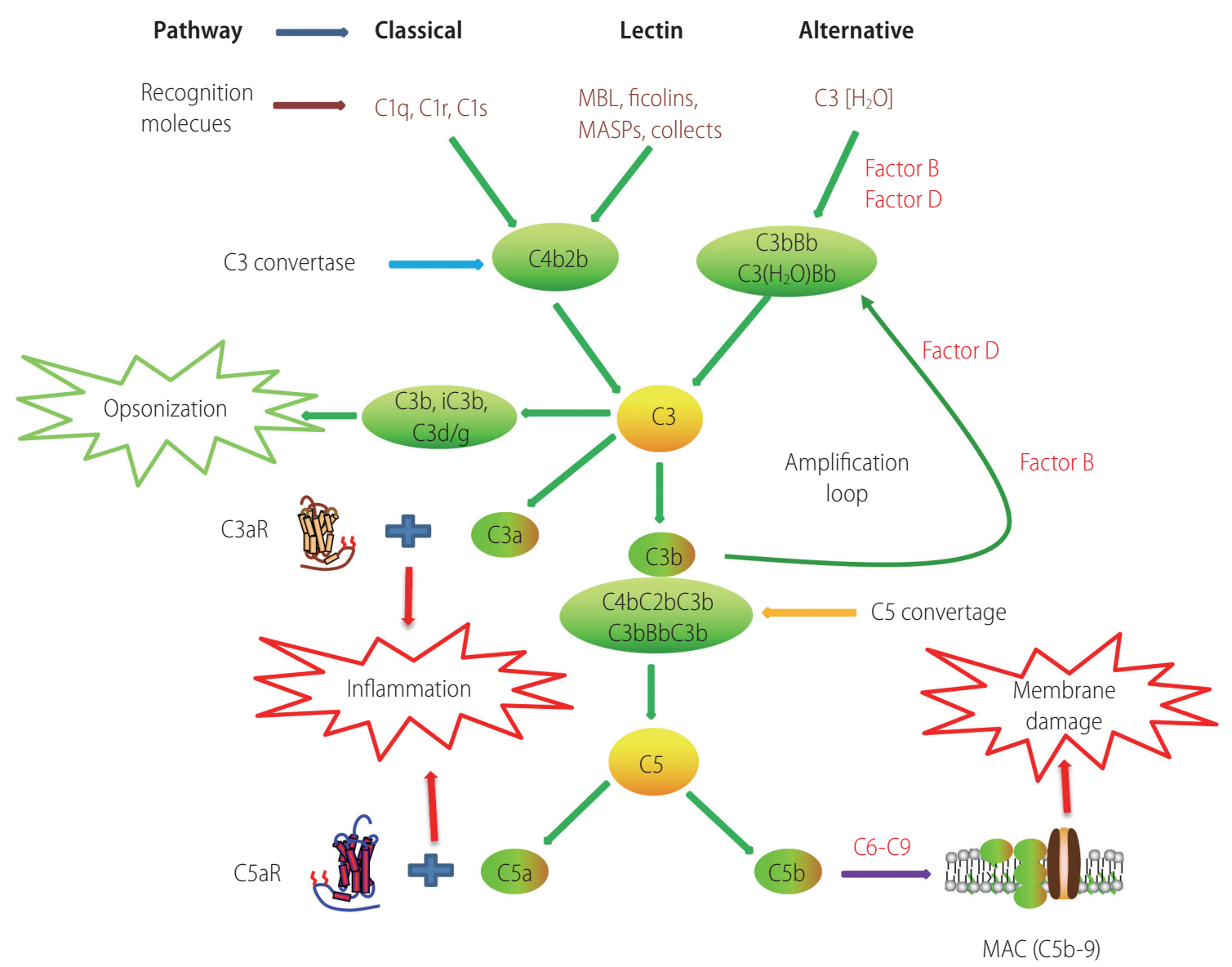

Figure 1. Schematic overview of the complement cascade illustrating three activation pathways (classical, lectin, and alternative) and summarizing the biological effects of complement activation products. MAC, membrane attack complex. 
ress of alcoholic liver disease (ALD). ${ }^{21-23}$ In this mini-review, we used five search engines, that is, MEDLINE, PubMed, EMBASE, Web of Science, and Biosos Preview, and we screened out 218 papers in this field. We will discuss the recent findings on the role of complement activation and regulation and oxidative stress in the progression of ALD, which might help us to better understand the pathogenesis of ALD and provide some novel potential therapeutic strategy for ALD.

\section{COMPLEMENT AND ALCOHOL-INDUCED LIVER DISEASE}

Studies have reported that the complement system is activated in ALD and participates in different stages of its pathogenesis, including alcoholic fatty liver disease (AFLD), alcoholic hepatitis $(\mathrm{AH})$, alcoholic hepatic fibrosis, and cirrhosis (Table 1). ${ }^{21-23}$ In this mini-review, the role and mechanism of the complement system in different stages of ALD are briefly summarized, especially focusing on the recent relevant progress.

\section{The complement system participates in AFLD}

The liver is a predominant organ for the metabolism of alcohol and lipids. ${ }^{24}$ It is generally accepted that in the pathogenesis of AFLD, alcohol, as the "first strike," causes the disorder of lipid metabolism and the heterotopic deposition of triglycerides in hepatocytes. The reaction between reactive oxygen species (ROS) and accumulated triglycerides in hepatocytes is lipotoxic and acts as the "second strike" in the AFLD process. ${ }^{25}$ However, how the complement system is involved in this process remains unclear.

Barry and McGivan ${ }^{22}$ reported that acetaldehyde, an intermediate product of alcohol metabolism, can bind to hepatocyte plasma membranes, resulting in the activation of $\mathrm{C} 3$ by causing a structural change in the surface of the plasma membrane. A previous study in rats revealed that the expression of complement components $\left(C_{1}, C_{3}\right.$, and $\left.C 8\right)$ was elevated, while the expression of complement receptor 1 (CR1)-related protein y (Crry) and CD59 was reduced after long-term alcohol feeding. ${ }^{26}$ Wlazlo et al. ${ }^{5}$ showed that the serum level of C3a, an indicator of C3 activation, was associated with liver steatosis and hepatocellular injury in individuals who are chronic alcohol abusers. In mouse models of ethanol feeding, Bykov et al. ${ }^{27}$ found that $\mathrm{C}^{+/+}$mice developed AFLD, while $\mathrm{C}^{-1-}$ mice had reduced lipid accumulation in the liver. In a study of the role of C3 in AFLD, the authors suggested that C3a binding to the receptor $\mathrm{C} 3 \mathrm{aR}$, which is highly expressed on Kupffer cells, can promote the inflammatory response and stimulate the release of the inflammatory cytokine tumor necrosis factor-a (TNF-a). TNF-a participates in AFLD, either directly or indirectly, through the induction of insulin resistance. ${ }^{5}$ Pritchard et al. $^{28}$ also proved that $\mathrm{C}^{-/-}$mice did not develop AFLD or increase triglycerides in the circulation, but the levels of serum alanine aminotransferase (ALT) and inflammatory cytokines were significantly higher. On the contrary, $\mathrm{C}^{-1-}$ mice had increased hepatic triglycerides and developed AFLD, whereas they did not show increased levels of ALT or inflammatory cytokines after ethanol

Table 1. Important research of the complement system in alcoholic liver disease

\begin{tabular}{|c|c|c|}
\hline Alcoholic liver disease & Complement component & Species \\
\hline \multicolumn{3}{|l|}{ Alcoholic fatty liver disease } \\
\hline Wlazlo et al. ${ }^{5}$ & $\mathrm{C} 3 \mathrm{a}$ & Human \\
\hline Bykov et al. ${ }^{27}$ & $\mathrm{C} 3$ & Mouse \\
\hline Pritchard et al. ${ }^{28}$ & $C 3, C 5$ & Mouse \\
\hline Zhong et al. ${ }^{32}$ & $\mathrm{C} 3$ & Mouse and human \\
\hline \multicolumn{3}{|l|}{ Alcoholic hepatitis } \\
\hline Shen et al. ${ }^{37}$ & $\mathrm{Clq}, \mathrm{C} 3, \mathrm{C} 5$, and $\mathrm{C} 5 \mathrm{aR}$ & Human \\
\hline McCullough et al. ${ }^{41}$ & Factor D & Mouse \\
\hline Fan et $a^{42}$ & $\mathrm{CFI}$ and $\mathrm{s} C 5 \mathrm{~b} 9$ & Human \\
\hline \multicolumn{3}{|c|}{ Alcoholic hepatic fibrosis and cirrhosis } \\
\hline Hillebrandt et al. ${ }^{43}$ & C5 & Mouse and human \\
\hline Baumann al..$^{50}$ & $\mathrm{C} 3$ & Human \\
\hline
\end{tabular}


feeding. Another study showed that more cholesterol was deposited in the liver of $\mathrm{C}^{-/-}$mice than in the liver of $\mathrm{C}^{+/+}$mice, and $\mathrm{C}^{-1-}$ mice had higher levels of serum triglycerides and cholesterol than $\mathrm{C}^{+/+}$mice. ${ }^{23}$ These results show that $\mathrm{C} 3$ and $\mathrm{C} 5$ play different roles in the development of AFLD. However, the mechanisms by which the complement system is involved in AFLD are still incompletely understood.

Ethanol consumption increases the generation of ROS and decreases the antioxidant activity, leading to the increase of oxidative stress. Increased oxidative stress from ethanol exposure is a critical element for the pathogenesis of ALD. ${ }^{29}$ Growing evidence suggests that the interaction between complement activation and oxidative stress plays crucial roles in ALD. ${ }^{29-31}$ Under basal conditions, the anaphylatoxin C $3 a$ and $C 5 a$ receptors are highly expressed in Kupffer cells. Ethanol-induced complement activation results in the generation of the anaphylatoxins $\mathrm{C} 3 \mathrm{a}$ and $\mathrm{C} 5 \mathrm{a}$, which bind to the receptors on Kupffer cells, and subsequently increases the expression of inflammatory cytokines and releases the ROS, contributing to ALD. ${ }^{28}$ However, the mechanisms underlying the interaction between complement activation and oxidative stress in ALD remain unclear. A recent study found that C3a and its degraded form, C3a-des-Arg (also known as acylation stimulating protein [Asp]), contribute to the pathogenesis of AFLD. Asp binding to its receptor C5aR2 promotes the expression of cytochrome P450 family 2, subfamily E, polypeptide 1, which induces the production of ROS. The induced oxidative stress subsequently leads to the increased expression of glycine tRNA-derived fragments (Gly-tRFs). Gly-tRF antisense inhibitor treatment can prevent the development of AFLD by reducing fatty acid synthesis and increasing fatty acid oxidation through regulating the SIRT1 signaling pathway in ethanol-fed mice. This study bridges the knowledge gap between the complement system, oxidative stress, and steatosis through elucidating the role of Gly-tRFs in ALD. $^{32}$

\section{The complement system participates in alcoholic hepatitis}

Different from AFLD, except for the deposition of triglycerides in hepatocytes, AH is also characterized by the infiltration of inflammatory cells, elevated inflammatory cytokine levels, increased serum transaminase levels, and liver injury. Previous studies have shown that inflammatory cytokines play an important role in the occurrence and development of ALD. ${ }^{33,34}$ In AH, inflammatory cytokine levels were elevated, leading to liver cell dysfunction and continued tissue damage. ${ }^{35}$ The complement system is also associated with the pathogenesis of $\mathrm{AH}$. Cohen et al. ${ }^{36}$ reported that $\mathrm{C} 1 \mathrm{q}$ deficiency abolishes the activation of the $\mathrm{CP}$, reduces the expression of inflammatory cytokines, and attenuates liver tissue injury. These results were further confirmed in a study of an alcoholic liver model in mice by Smathers et al. ${ }^{34}$ Moreover, in AH patients, C1q and C5 levels were significantly increased, and the expression of $\mathrm{C} 5 \mathrm{aR}$ was also upregulated in the Mallory-Denk body forming cells, which are the major features of ongoing inflammation in $\mathrm{AH}^{37,38}$ These studies showed that complement activation is involved in the occurrence of $\mathrm{AH}$ and the impairment of liver function. The underlying mechanism may be that there is a crosstalk between toll-like receptors (TLRs) and C3aR and C5aR in $\mathrm{AH}^{21,37,39,40} \mathrm{TLRs}$ belong to the pattern recognition receptor family, which can bind to damage-associated molecular patterns or pathogen-associated molecular patterns (PAMPs). PAMPs mainly refer to bacterial metabolites, including bacterial lipopolysaccharide, peptidoglycan, RNA, and DNA, which can reach the liver upon alcohol-induced intestinal microecology imbalance, subsequently initiating the innate immune response and inducing the expression of inflammatory cytokines (such as TNF- $a$ and interleukin-6). In addition, PAMPs increase lipid deposition and inflammatory infiltration in hepatocytes. McCullough et al. ${ }^{41}$ found that complement FD promotes the clearance of apoptotic cells and maintains tissue homeostasis in AH and suggested that inappropriate complement activation likely delays the clearance of apoptotic cells and impairs healing/recovery in ALD. Fan et al. ${ }^{42}$ found that complement activation is expected to be a diagnostic and prognostic indicator for patients with AH. However, the detailed mechanisms of complement function in $\mathrm{AH}$ need to be further clarified.

\section{The complement system participates in alcoholic hepatic fibrosis and cirrhosis}

Hepatic fibrosis is an early event of cirrhosis. Alcoholic hepatic fibrosis is a process of damage and repair of the liver after longterm alcohol exposure, accompanied by the excessive accumulation and rearrangement of the extracellular matrix, the development of $\mathrm{AH}$, and the formation of pseudolobules. These pathological changes cause damage to the liver structure and ultimately progress to liver cirrhosis. A previous study showed that the expression of the $C 5$ gene is involved in liver fibrogenesis, and inhibition of the C5aR1 attenuates liver fibrosis in mice. ${ }^{43}$ Moreover, $\mathrm{C} 5$ has a causal role in fibrogenesis across species between humans and 
mice. A number of studies have confirmed a decrease in the level of serum complement proteins, including $\mathrm{C} 1, \mathrm{C} 3, \mathrm{C} 4, \mathrm{C} 5$, and FB, in patients with alcoholic cirrhosis. ${ }^{44-47}$ Other studies further revealed that serum concentrations of $\mathrm{C} 3, \mathrm{C} 4 \mathrm{a}$, and $\mathrm{C} 5 \mathrm{a}$ had a negative relationship with liver fibrosis stages and the Child-Pugh score. ${ }^{48-50}$ These studies show that the levels of complement components may be an indicator of liver fibrosis or cirrhosis stage. ${ }^{51}$
There are two possible mechanisms: the reduction of complement synthesis after severe liver injury and excessive complement depletion. ${ }^{52}$ However, the results of two studies showed some discrepancies; the serum complement concentration was normal, and no significant differences were observed in patients with alcoholic cirrhosis. ${ }^{53,54}$ Further studies are required to explore the mechanisms underlying the role of the complement system in the
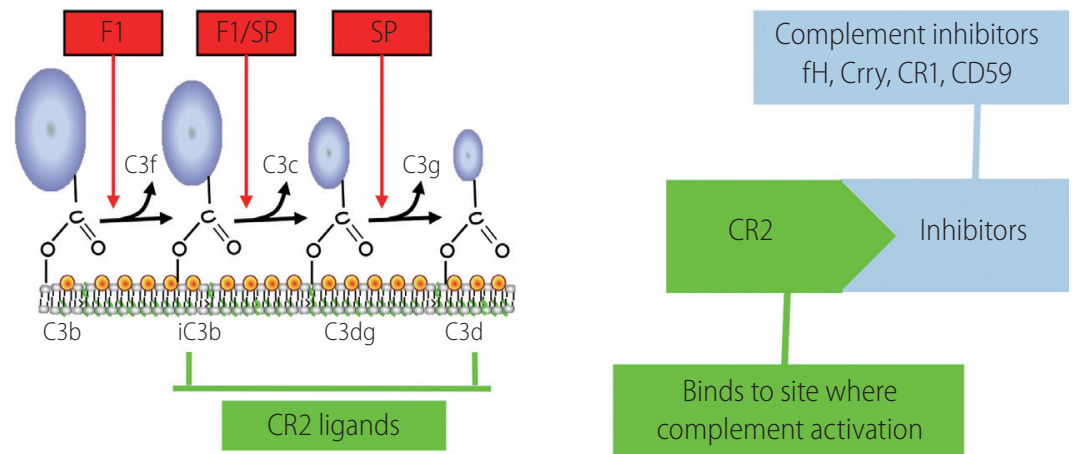

Figure 2. Schematic of CR2 site-targeted complement inhibitors. The CR2 moiety of the fusion protein binds the C3 degradation products iC3b, C3dg, and C3d that are covalently attached at sites of complement activation. Complement inhibitory constructs that have previously been prepared and characterized are CR2-Crry (murine inhibitor of C3 activation), CR2-CR1 (human inhibitor of C3 activation), CR2-fH (murine and human inhibitor of the alternative complement pathway), and CR2-CD59 (murine and human inhibitor of MAC formation). F1, factor 1; SP, serum protease; CR1/2, complement receptor 1/2; Crry, complement receptor-1 related protein y.

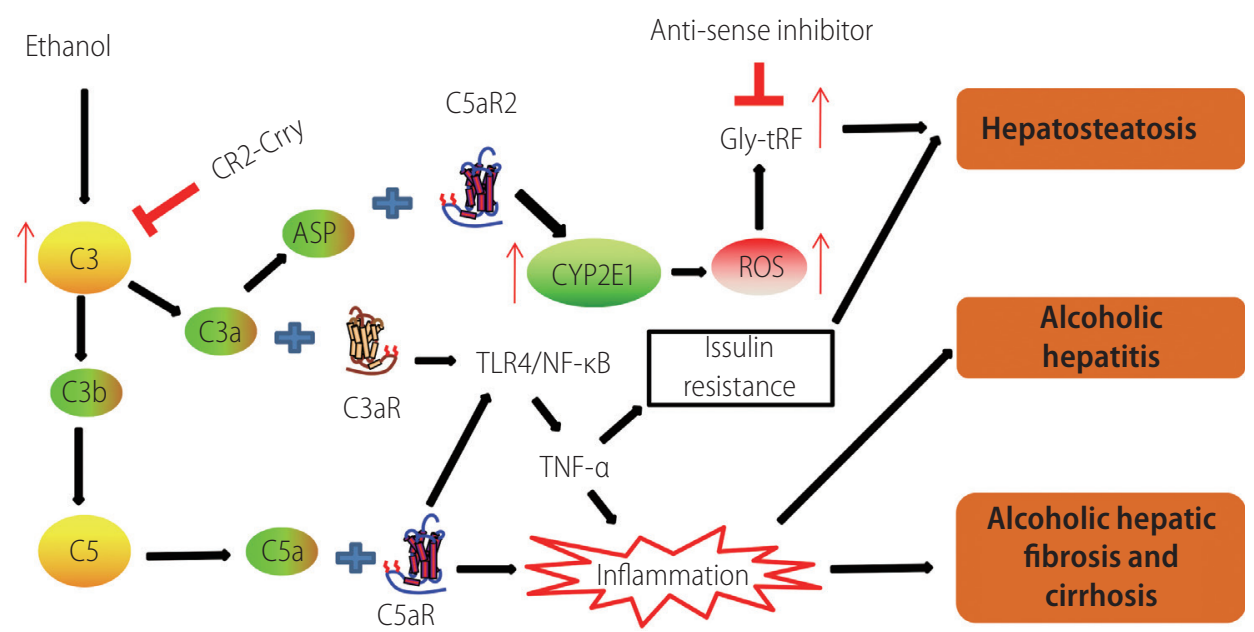

Figure 3. Schematic graph showing that the complement system participates in the development of alcohol-induced liver disease. C3 convertase cleaves C3 to form C3a and C3b. ASP is the degraded product of C3a. C3b is an important component of C5 convertase. CR2-Crry is a site-targeted complement inhibitor that blocks all complement pathways at the C3 activation step. When anaphylatoxins C3a and C5a bind with their respective receptors, the TLR4/NF-KB pathway can be activated, resulting in the release of the inflammatory cytokine TNF-a, which participates in AFLD, either directly or indirectly, through the induction of insulin resistance. C3a and ASP bind to their receptor C5aR2 to promote the expression of Cyp2E1, which induces the production of ROS. The induced oxidative stress subsequently leads to the increased expression of Gly-tRF, which leads to AFLD via regulating the SIRT1 signaling pathway. The inflammatory response contributes to the development and progression of ALD. CR2, complement receptor 2; Crry, complement receptor 1-related protein y; ASP, acylation stimulating protein; Cyp2E1, cytochrome P450 family 2, subfamily E, polypeptide 1; GlytRFs, glycine tRNA-derived fragments; ROS, reactive oxygen species; TLR, toll-like receptor; TNF-a, tumor necrosis factor-alpha; AFLD, alcoholic fatty liver disease; ALD, alcohol-induced liver disease. 
occurrence and development of advanced liver disease, as complement regulation may be a potential strategy for reversing the progress of liver fibrosis.

\section{COMPLEMENT REGULATION IN ALCOHOLIC LIVER DISEASE}

In physiological conditions, there is a delicate balance between complement activation and regulation. Insufficient regulation or excessive activation can result in a large variety of disorders. ${ }^{55}$ The host expresses a variety of both fluid-phase and membranebound inhibitory proteins to regulate the location and activity of complement factors. Soluble inhibitors of the complement system include $\mathrm{C} 1$ inhibitor, $\mathrm{C} 4$ binding protein, factor I, factor $\mathrm{H}(\mathrm{FH})$, and MBL-associated protein of 44 kilodalton, which can be distributed throughout the body with the blood. ${ }^{56}$ These soluble inhibitors have the characteristics of systematic regulation, which easily lead to immune regulation imbalance and lack of targeting. Membrane-bound inhibitory proteins are anchored on the membrane surface of specific cells to protect the host from complement attack. These membrane-bound inhibitors can be divided into two categories. The first includes inhibitors of the formation of C3 convertases, including CR1, decay accelerating factor, and membrane cofactor protein. Crry is expressed in rodents, which is similar to human CR1 in structure and function. The other is represented by CD59, which competes to combine with $\mathrm{C} 8$ and C9, further inhibiting MAC formation. ${ }^{57}$

Tissue targeting is a promising complement regulation strategy, which provides a safer and considerably more effective therapeutic approach compared with a systemic (untargeted) complement inhibition. One such targeting approach involves linking a complement inhibitor to a fragment of CR2 that recognizes $\mathrm{C3}$ activation products deposited at sites of complement activation (Fig. 2). Complement inhibitors such as Crry, FH, or CD59 will go directly to the complement-attacked tissue after systemic infusion and locally inhibit complement without compromising the systemic complement function. ${ }^{55}$ CR2-Crry, a site-targeted complement inhibitor, can suppress $\mathrm{C} 3$ activation through inhibition of $\mathrm{C} 3$ convertase, resulting in a reduction in the levels of $\mathrm{C} 3 \mathrm{a}, \mathrm{C} 3 \mathrm{~b}$, and Asp. A recent study showed that suppression of $\mathrm{C} 3$ activation can protect against the injury of steatosis and inflammation in ALD. ${ }^{32}$ Therefore, targeted complement inhibitors may become a potential drug to protect against both infiammatory response syndrome and hepatic steatosis for AFLD patients (Fig. 3). ${ }^{32}$
According to the specific structure of complement molecules, complement mutants and complement peptides can also be used to regulate complement activity. ${ }^{58,59}$ Moreover, the crosstalk between the complement, coagulation, and fibrinolysis systems also plays an important role in complement regulation. As an example, thrombomodulin participates in complement regulation through two mechanisms. Thrombomodulin can enhance factor I-mediated inactivation of C3b on the cell surface. Moreover, thrombomodulin also accelerates the inactivation of anaphylatoxins C3a and C5a by regulating the activation of procarboxypeptidase $B{ }^{60,61}$ These strategies may be also applicable to the treatment of ALD.

\section{FUTURE PERSPECTIVE}

Recent advances in complement research have shown that the complement system acts an important regulator for each stage of ALD. The precise regulatory mechanisms of the complement system in the occurrence and development of ALD need to be further explored. A better understanding of the mechanisms by which the complement system affects ALD may help us identify novel therapeutic targets and provide a potential therapeutic approach to inhibit or reverse the progression of ALD. Based on the advances of the present research, targeted complement inhibitors and antisense inhibition of Gly-tRF may provide a therapeutic strategy for treating human ALD.

\section{Authors' contribution}

He SQ designed research; Zhou Y, Zhong FD and Yuan GD searched the relevant literatures; and Zhou $Y$ wrote the review; Zhong FD, Yuan GD and He SQ revised the review.

\section{Acknowledgements}

This work was supported in part by National Natural Science Foundation of China (81771674 and 81660103); The 111 Project (D17011); Guangxi Key Research and Development Plan (2018AD03001); Guangxi BaGui Scholars; Molecular Medicine of Liver Injury and Repair Collaborative Innovation Center; Guangxi Key Laboratory of Molecular Medicine in Liver Injury and Repair (GXLIRMMKL-201806); and Special projects of local science and technology development guided by the central government (Declaration No 001176111039). 


\section{Conflicts of Interest}

The authors have no conflicts to disclose.

\section{REFERENCES}

1. Merle NS, Noe R, Halbwachs-Mecarelli L, Fremeaux-Bacchi V, Roumenina LT. Complement system part II: role in immunity. Front Immunol 2015;6:257.

2. Ricklin D, Hajishengallis G, Yang K, Lambris JD. Complement: a key system for immune surveillance and homeostasis. Nat Immunol 2010;11:785-797.

3. Gasque P. Complement: a unique innate immune sensor for danger signals. Mol Immunol 2004;41:1089-1098.

4. Fey $G$, Colten HR. Biosynthesis of complement components. Fed Proc 1981;40:2099-2104.

5. Wlazlo N, van Greevenbroek MM, Ferreira I, Jansen EH, Feskens EJ, van der Kallen CJ, et al. Activated complement factor 3 is associated with liver fat and liver enzymes: the CODAM study. Eur J Clin Invest 2013;43:679-688.

6. Colten HR, Strunk RC. Synthesis of complement components in liver and at extrahepatic sites. In: Whaley K, Loos M, Weiler JM, eds. Complement in Health and Disease. Immunology and Medicine. Vol 20. Dordrecht: Springer, 1993:127-158.

7. Walport MJ. Complement. First of two parts. N Engl J Med 2001;344: 1058-1066.

8. Bohlson SS, Fraser DA, Tenner AJ. Complement proteins C1q and $M B L$ are pattern recognition molecules that signal immediate and long-term protective immune functions. Mol Immunol 2007;44:3343.

9. Wallis R, Mitchell DA, Schmid R, Schwaeble WJ, Keeble AH. Paths reunited: initiation of the classical and lectin pathways of complement activation. Immunobiology 2010;215:1-11.

10. Schraufstatter IU, Khaldoyanidi SK, DiScipio RG. Complement activation in the context of stem cells and tissue repair. World J Stem Cells 2015;7:1090-1108.

11. Fearon DT, Austen KF, Ruddy S. Formation of a hemolytically active cellular intermediate by the interaction between properdin factors $B$ and $D$ and the activated third component of complement. J Exp Med 1973;138:1305-1313.

12. Bajic G, Degn SE, Thiel S, Andersen GR. Complement activation, regulation, and molecular basis for complement-related diseases. EMBO J 2015;34:2735-2757.

13. Noris M, Remuzzi G. Overview of complement activation and regulation. Semin Nephrol 2013;33:479-492.

14. Hajishengallis G, Reis ES, Mastellos DC, Ricklin D, Lambris JD. Novel mechanisms and functions of complement. Nat Immunol 2017;18:1288-1298.
15. Ehrnthaller C, Ignatius A, Gebhard F, Huber-Lang M. New insights of an old defense system: structure, function, and clinical relevance of the complement system. Mol Med 2011;17:317-329.

16. Stephan AH, Barres BA, Stevens B. The complement system: an unexpected role in synaptic pruning during development and disease. Annu Rev Neurosci 2012;35:369-389.

17. Giang J, Seelen MAJ, van Doorn MBA, Rissmann R, Prens EP, Damman J. Complement activation in inflammatory skin diseases. Front Immunol 2018;9:639.

18. Yiu WH, Li RX, Wong DWL, Wu HJ, Chan KW, Chan LYY, et al. Complement C5a inhibition moderates lipid metabolism and reduces tubulointerstitial fibrosis in diabetic nephropathy. Nephrol Dial Transplant 2018;33:1323-1332.

19. Schmidt CQ, Verschoor A. Complement and coagulation: so close, yet so far. Blood 2017;130:2581-2582.

20. Khan MA, Assiri AM, Broering DC. Complement and macrophage crosstalk during process of angiogenesis in tumor progression. J Biomed Sci 2015;22:58.

21. Roychowdhury S, McMullen MR, Pritchard MT, Hise AG, van Rooijen $\mathrm{N}$, Medof ME, et al. An early complement-dependent and TLR4-independent phase in the pathogenesis of ethanol-induced liver injury in mice. Hepatology 2009;49:1326-1334.

22. Barry RE, McGivan JD. Acetaldehyde alone may initiate hepatocellular damage in acute alcoholic liver disease. Gut 1985;26:1065-1069.

23. Bavia L, de Castro ÍA, Cogliati B, Dettoni JB, Alves VA, Isaac L. Complement $C 5$ controls liver lipid profile, promotes liver homeostasis and inflammation in C57BL/6 genetic background. Immunobiology 2016;221:822-832.

24. Jeon S, Carr R. Alcohol effects on hepatic lipid metabolism. J Lipid Res 2020;61:470-479.

25. Koteish A, Diehl AM. Animal models of steatosis. Semin Liver Dis 2001;21:89-104.

26. Järveläinen $H A$, Väkevä $A$, Lindros KO, Meri S. Activation of complement components and reduced regulator expression in alcoholinduced liver injury in the rat. Clin Immunol 2002;105:57-63.

27. Bykov I, Junnikkala S, Pekna M, Lindros KO, Meri S. Complement C3 contributes to ethanol-induced liver steatosis in mice. Ann Med 2006;38:280-286.

28. Pritchard MT, McMullen MR, Stavitsky AB, Cohen J, Lin F, Edward Medof $M$, et al. Differential contributions of $C 3, C 5$, and decayaccelerating factor to ethanol-induced fatty liver in mice. Gastroenterology 2007;132:1117-1126.

29. Galligan JJ, Smathers RL, Shearn CT, Fritz KS, Backos DS, Jiang H, et al. Oxidative stress and the er stress response in a murine model for early-stage alcoholic liver disease. J Toxicol 2012;2012:207594.

30. Leung TM, Nieto N. CYP2E1 and oxidant stress in alcoholic and nonalcoholic fatty liver disease. J Hepatol 2013;58:395-398.

31. Louvet A, Mathurin P. Alcoholic liver disease: mechanisms of 
injury and targeted treatment. Nat Rev Gastroenterol Hepatol 2015;12:231-242.

32. Zhong F, Hu Z, Jiang K, Lei B, Wu Z, Yuan G, et al. Complement C3 activation regulates the production of tRNA-derived fragments GlytRFs and promotes alcohol-induced liver injury and steatosis. Cell Res 2019;29:548-561.

33. Wang HJ, Gao B, Zakhari S, Nagy LE. Inflammation in alcoholic liver disease. Annu Rev Nutr 2012;32:343-368.

34. Smathers RL, Chiang DJ, McMullen MR, Feldstein AE, Roychowdhury $S$, Nagy LE. Soluble IgM links apoptosis to complement activation in early alcoholic liver disease in mice. Mol Immunol 2016;72:9-18.

35. McCullough RL, McMullen MR, Das D, Roychowdhury S, Strainic $M G$, Medof ME, et al. Differential contribution of complement receptor C5aR in myeloid and non-myeloid cells in chronic ethanolinduced liver injury in mice. Mol Immunol 2016;75:122-132.

36. Cohen JI, Roychowdhury S, McMullen MR, Stavitsky AB, Nagy LE. Complement and alcoholic liver disease: role of $\mathrm{C} 1 \mathrm{q}$ in the pathogenesis of ethanol-induced liver injury in mice. Gastroenterology 2010;139:664-674.e1.

37. Shen $H$, French BA, Liu H, Tillman BC, French SW. Increased activity of the complement system in the liver of patients with alcoholic hepatitis. Exp Mol Pathol 2014;97:338-344.

38. French SW, Bardag-Gorce F, Li J, French BA, Oliva J. Mallory-Denk body pathogenesis revisited. World J Hepatol 2010;2:295-301.

39. Liu H, Li J, Tillman B, Morgan TR, French BA, French SW. TLR3/4 signaling is mediated via the NFKB-CXCR4/7 pathway in human alcoholic hepatitis and non-alcoholic steatohepatitis which formed Mallory-Denk bodies. Exp Mol Pathol 2014;97:234-240.

40. Raby AC, Holst B, Davies J, Colmont C, Laumonnier Y, Coles B, et al. TLR activation enhances $C 5 a$-induced pro-inflammatory responses by negatively modulating the second $\mathrm{C} 5$ a receptor, $\mathrm{C} 5 \mathrm{~L} 2$. Eur J Immunol 2011;41:2741-2752.

41. McCullough RL, McMullen MR, Sheehan MM, Poulsen KL, Roychowdhury S, Chiang DJ, et al. Complement Factor D protects mice from ethanol-induced inflammation and liver injury. Am J Physiol Gastrointest Liver Physiol 2018;315:G66-G79.

42. Fan X, McCullough RL, Huang E, Bellar A, Kim A, Poulsen KL, et al. Diagnostic and prognostic significance of complement in patients with alcohol-associated hepatitis. Hepatology. 2020 Jun 17. doi: 10.1002/hep.31419.

43. Hillebrandt S, Wasmuth HE, Weiskirchen R, Hellerbrand C, Keppeler $H$, Werth $A$, et al. Complement factor 5 is a quantitative trait gene that modifies liver fibrogenesis in mice and humans. Nat Genet 2005;37:835-843.

44. Finlayson ND, Krohn K, Fauconnet MH, Anderson KE. Significance of serum complement levels in chronic liver disease. Gastroenterology 1972;63:653-659.

45. Potter BJ, Trueman AM, Jones EA. Serum complement in chronic liver disease. Gut 1973;14:451-456.

46. Potter BJ, Elias E, Fayers PM, Jones EA. Profiles of serum complement in patients with hepatobiliary diseases. Digestion 1978;18:371383.

47. Ellison RT 3rd, Horsburgh CR Jr, Curd J. Complement levels in patients with hepatic dysfunction. Dig Dis Sci 1990;35:231-235.

48. Deng Y, Zhao H, Zhou J, Yan L, Wang G; China HepB-Related Fibrosis Assessment Research Group. Complement $5 \mathrm{a}$ is an indicator of significant fibrosis and earlier cirrhosis in patients chronically infected with hepatitis B virus. Infection 2017;45:75-81.

49. Behairy BE, El-Mashad GM, Abd-Elghany RS, Ghoneim EM, Sira MM. Serum complement $\mathrm{C} 4 \mathrm{a}$ and its relation to liver fibrosis in children with chronic hepatitis C. World J Hepatol 2013;5:445-451.

50. Baumann M, Witzke O, Canbay A, Patschan S, Treichel U, Gerken $G$, et al. Serum C3 complement concentrations correlate with liver function in patients with liver cirrhosis. Hepatogastroenterology 2004;51:1451-1453.

51. Ferrín G, Rodríguez-Perálvarez $M$, Aguilar-Melero P, Ranchal I, Llamoza C, Linares $\mathrm{Cl}$, et al. Plasma protein biomarkers of hepatocellular carcinoma in HCV-infected alcoholic patients with cirrhosis. PLoS One 2015;10:e0118527.

52. Homann C, Varming K, Høgåsen K, Mollnes TE, Graudal N, Thomsen $A C$, et al. Acquired C3 deficiency in patients with alcoholic cirrhosis predisposes to infection and increased mortality. Gut 1997;40:544549.

53. Gluud C, Jans H. Circulating immune complexes and complement concentrations in patients with alcoholic liver disease. J Clin Pathol 1982;35:380-384.

54. Fox RA, Dudley FJ, Sherlock $S$. The serum concentration of the third component of complement beta-1C-beta-1A in liver disease. Gut 1971;12:574-578.

55. Thorgersen EB, Barratt-Due A, Haugaa H, Harboe M, Pischke SE, Nilsson $\mathrm{PH}$, et al. The role of complement in liver injury, regeneration, and transplantation. Hepatology 2019;70:725-736.

56. Varela JC, Tomlinson S. Complement: an overview for the clinician. Hematol Oncol Clin North Am 2015;29:409-427.

57. Wu G, Hu W, Shahsafaei A, Song W, Dobarro M, Sukhova GK, et al. Complement regulator CD59 protects against atherosclerosis by restricting the formation of complement membrane attack complex. Circ Res 2009;104:550-558.

58. Fujita E, Farkas I, Campbell W, Baranyi L, Okada H, Okada N. Inactivation of $\mathrm{C} 5 \mathrm{a}$ anaphylatoxin by a peptide that is complementary to a region of C5a. J Immunol 2004;172:6382-6387.

59. Otto M, Hawlisch H, Monk PN, Müller M, Klos A, Karp CL, et al. C5a mutants are potent antagonists of the $\mathrm{C} 5$ a receptor (CD88) and of C5L2: position 69 is the locus that determines agonism or antagonism. J Biol Chem 2004;279:142-151.

60. Conway EM. Thrombomodulin and its role in inflammation. Semin 
Yi Zhou, et al.

Role of complement in alcoholic liver disease

Immunopathol 2012;34:107-125.

61. Delvaeye M, Noris M, De Vriese A, Esmon CT, Esmon NL, Ferrell G, et al. Thrombomodulin mutations in atypical hemolytic-uremic syndrome. N Engl J Med 2009;361:345-357. 